\title{
A DIGNIDADE DA PESSOA E O FUNDAMENTO DOS DIREITOS HUMANOS
}

\author{
THE HUMAN DIGNITY AND THE FUNDAMENTAL HUMAN RIGHTS
}

José Oliveira Ascensão*

\begin{abstract}
Resumo:
O apogeu dos direitos: luzes e sombra; A usura da referência à "eminente dignidade da pessoa humana"; a pessoa, como o ser que é digno; A formulação da noção de pessoa; A perda de sentido ético. A privacidade; Pessoa, homem, corpo e genoma; $\mathrm{O}$ anencefálico; $\mathrm{O}$ direito ao desenvolvimento da personalidade; A realização da personalidade; O outro: a comunhão; O Direito da Pessoa e a Incidência sobre a Teoria Geral do Direito Civil são os temas abordados por este Autor.

Palavras-chaves: Teoria Geral do Direito Civil. Noção de Pessoa. Dignidade da Pessoa Humana.
\end{abstract}

\begin{abstract}
:
The apogee of rights: light and shade. The use of the reference to the "eminent dignity of human being"; the person, as a dignity being. The formulation of the notion of person. The loss of ethical sense. Privacy. Person, man, body and genome. Anencephalic being. The right to the development of personality. The realization of personality. The other. The communion. The right of the person and the incidence on the general theory of private law are the subjects treated by this Author.
\end{abstract}

Keywords: General theory of the Private Law. Notion of Person. Dignity of the Person. Human Person.

1. O apogeu dos direitos: luzes e sombras

Entra-se no século XXI em fase de verdadeiro apogeu de Direitos Humanos. A civilização dos direitos, definitivamente, ganhou. Com mais ou menos relutância, todos a proclamam. Em nome dos direitos se faz a política, a economia, até a guerra. E o fervor é tanto que os direitos se multiplicam e sobrepõem. As organizações internacionais competem entre si no lançamento de novos catálogos de Direitos Humanos.

Mesmo no âmbito nacional a multiplicação se faz, através de uma pluralidade de fontes, muitas vezes repetitivas. Vários ramos do Direito estão implicados, sem haver grande coordenação entre os sectores respectivos. E assim:

- o Direito Civil apresenta-nos os direitos de personalidade

- o Direito Constitucional, os direitos fundamentais

Professor Catedrático de Direito Civil da Universidade de Lisboa. O Autor é convidado do Professor Associado Eduardo Carlos Bianca Bittar. 
-o Direito Internacional, os direitos humanos. ${ }^{1}$

A civilização dos direitos é evidente aos olhos do homem de hoje, mesmo do homem comum da nossa civilização. Tão evidente que ele dificilmente se dará conta que essa civilização é muito recente. Explode no século XVIII, que é o século da grande viragem do Ocidente. E explode radicalmente: a uma sociedade em que a sociedade política apelava aos deveres dos cidadãos sucede-se uma sociedade em que se apela aos direitos. Há uma passagem da comunidade sócio-política, de comunidade de deveres para comunidade de direitos; e até, nas formas mais adiantadas, comunidade de direitos sem deveres. Pelo menos, os deveres ocupam um lugar recuado, perante essa categoria nuclear que é representada pelos direitos humanos ou direitos do homem.

Já lá vão mais de dois séculos de expansão contínua. Neste domínio o traço marcante foi a noção de progresso, que se futurava ilimitado e sustentava a soberania do homem. Implicou muitos aspectos positivos, como aliás em todas as épocas históricas.

Mas nem todos os resultados foram tranquilizadores. Paralelamente, vimos cometerem-se as aberrações mais clamorosas, atingindo justamente o homem carregado de direitos. Não dou um único exemplo, porque determo-nos no singular faz perder de vista o colectivo. Apelo apenas à vossa imaginação. Tivemos sempre, nestes mais de dois séculos dos direitos do homem, as mais chocantes violações desse homem com os seus direitos invioláveis.

E todavia, a sociedade parecia orientar-se decididamente em direcção ao homem, a quem servia. O homem é colocado como o centro da vida organizada. Como tal, tudo se lhe oferece.

O que se lhe oferece é, antes de mais, a adulação. Na propaganda política. Na publicidade omnipresente. Nos meios de comunicação. Tudo a reboque das sondagens. "Você merece...". Merece ser feliz, naturalmente.

Então, porque não é feliz?

O expandir dos direitos do homem no âmbito internacional é também grande, absorvendo progressivamente os espaços ainda arredios ao sistema. Mas não podemos deixar de ficar perturbados quando verificamos que afinal muitos dos que ditam as regras internacionais - obviamente, para defesa dos direitos do homem - têm as mãos sujas. E ninguém repara, a não ser quando individualmente algum cai em desgraça. E os outros?

Por que é que surge em uníssono a campanha contra um Myanmar violador, quando na realidade foi sempre assim? Que têm que ver com isso os direitos humanos?

Mais precisamente ainda: vemos na arena internacional os Direitos Humanos transformarem-se em arma de arremesso. Quando um país ataca outro, é sempre com o

Na seqüência do proclamado por foros mundiais, regionais ou supranacionais. 
nobre intuito de defender os Direitos humanos. Como assim? São sempre os que têm a força quem peleja pelos direitos humanos, e os mais fracos quem os viola?

2. A usura da referência à "eminente dignidade da pessoa humana"

Mas não pretendemos desviar-nos do nosso objectivo.

Olhamos à volta e encontramos um assentimento quase universal na outorga ou reconhecimento dos direitos humanos.

O fundamento dessa atribuição de direitos humanos é, igualmente, quase universal: os direitos humanos fundam-se na "eminente dignidade da pessoa humana". A frase deve dizer-se inteira, porque é assim que ela é por todo o lado pronunciada.

Universalizou-se, pois, não apenas a referência aos direitos humanos, como também à eminente dignidade da pessoa humana. Podemos dizer que estas expressões passaram a ser uma das âncoras da convergência universal, porque todos as utilizam, sem suscitar ondas, nos foros nacionais e internacionais.

E aí temos que parar e pensar, porque semelhante concordância esconde um grande perigo.

É como se, de tanto repetidas, as afirmações fossem gastando o sentido; e quando nos interrogamos sobre o que significam verificamos que são fórmulas vazias, afirmações sem conteúdo, porque este se foi esbatendo ao longo dos tempos, das bocas e dos ouvidos.

Perguntamos: de onde vem então essa dignidade (eminente) da pessoa humana?

Isso já se não diz; e, todavia, seria essencial dizê-lo. Porque se não assentarmos sobre a razão de tal dignidade a afirmação não tem substância. Ela é compatível com entendimentos contraditórios que se dizem simultaneamente professar sobre a pessoa, cuja dignidade se proclama. A afirmação retórica da dignidade da pessoa humana esconde assim o vazio quanto ao conteúdo que se atribui à pessoa cuja, dignidade seria proclamada. ${ }^{2}$

Não é raro proceder-se assim. A Declaração Universal da UNESCO sobre o Genoma Humano e os Direitos do Homem oferece-nos uma ilustração categórica. Quando os estudos sobre o genoma humano se foram desenvolvendo, a UNESCO emitiu uma Declaração solene cujo art. 1 continha esta afirmação: o genoma humano é património comum da humanidade.

\footnotetext{
2 "Falar da dignidade humana sem que se situe esta idéia no quadro de uma ética e antropologia filosófica determinada resulta lançar o valor que ela representa no vazio dos discursos políticos e jurídicos": BARRETTO, Vicente de Paulo. A idéia de pessoa humana e os limites da Bioética. In: BARBOSA, Heloísa Helena et al (Orgs.). Novos temas de biodireito e bioética. Rio de Janeiro/São Paulo: Renovar, 2003. 219.
} 
A frase foi recebida com admiração e aplauso. Mas com o tempo passou-se à reflexão e a conclusão impôs-se: a afirmação não tinha qualquer sentido. Por isso acabou por ser alterada, sendo substituída por um texto vago: "Num sentido simbólico ele [o genoma humano] é património da humanidade". É significativo do grande risco que pesa sobre nós, consistente na banalização dos grandes princípios.

Particularmente se tivermos em conta que esse deslizamento é acompanhado pela banalização dos direitos. No século XVIII seriam as grandes liberdades que estavam em causa. Mas mesmo então fez-se sentir logo o aproveitamento interesseiro. É assim que a burguesia vitoriosa coloca a par dos direitos mais elevados o direito de propriedade: "Sendo a propriedade um direito inviolável e sagrado...". E quando os escritores, que eram os impulsionadores ideológicos das novas correntes, quiseram defender os próprios privilégios sobre os seus escritos, logo invocaram direitos de propriedade: "a mais sagrada de todas as propriedades" até.

Com o tempo, a banalização dos direitos proclamados acentuou-se. Os direitos de nova geração, sociais, culturais, empresariais e outros vão-se multiplicando, ao sabor dos lóbis. Isto implica um esvaziamento dos direitos humanos, pois estes direitos vão disputar o espaço aos direitos mais nobres e subverter a escala de valores.

Manifestações mais recentes põem-nos em guarda contra estes movimentos. Limitamo-nos a dar dois exemplos.

\section{I - Direitos das pessoas colectivas}

Cultores do ramo dos Direitos da Personalidade incluem entre estes os direitos das pessoas colectivas. ${ }^{3}$

É algo verdadeiramente paradoxal. Se os direitos da pessoa se fundam na dignidade da pessoa, como admitir que os direitos que devem exprimir a essência da pessoa sejam atribuídos a pessoas colectivas? Portanto, a meras organizações sociais ou menos ainda, a puras estruturas jurídicas que quantas vezes só existem no papel? Há um esvaziamento total daquilo que deveria depender da dignidade da pessoa.

II - Direitos dos animais

É uma moda falar-se nos direitos doa animais, dentro da paixão pela novidade que percorre constantemente as hostes intelectuais.

Mas direitos dos animais, como? Só o homem pode ter direitos, porque o direito é realidade cultural. $\mathrm{O}$ animal pode e deve ter protecção, mas falar em direitos dos animais é, queira-se ou não, degradar gravemente o homem.

Que sentido tem então continuar a aparentar convergência na eminente dignidade da pessoa humana?

\footnotetext{
3 É o caso entre nós de SOUSA, Rabindranath Capelo de. O direito geral de personalidade. Coimbra: Coimbra Editora, 1995.
} 
Então os direitos só seriam qualificáveis como direitos do homem, de personalidade ou fundamentais, pela característica formal de a lei os outorgar e, provavelmente, os designar como tal. Mas na essência resumem-se aos que são legalmente dados e porque são dados. Não correspondem a nenhuma essência própria que funde uma categoria que se imponha como tal, porque manifestaria a eminente dignidade da pessoa humana.

Com a consequência que nem a Constituição asseguraria qualquer estabilidade aos direitos outorgados. Os direitos que contempla só são fundamentais porque de lá constam. Eliminada essa característica formal, nada os caracterizaria como direitos fundamentais.

Teríamos então que a "dignidade da pessoa humana" não daria afinal o critério para determinar quais os direitos que devem ou não ser reconhecidos constitucionalmente como fundamentais.

\section{A pessoa, como o ser que é digno}

Por outro lado, não podemos esquecer que a própria Constituição aponta "a dignidade da pessoa humana" como base da República (juntamente com a vontade popular) logo no art. 1. Dá-lhe assim um relevo particularíssimo, pois todos os restantes preceitos constitucionais lhe estariam subordinados no ponto de vista substancial. É análoga a situação à face do art. 1 III da Constituição Federal brasileira, por exemplo.

Não são casos isolados. Os apelos à dignidade da pessoa humana multiplicamse nas constituições, como fundamento geral. Inspiram-se todos no modelo paradigmático da Grundgesetz alemã, sem nunca atingirem todavia a grandeza lapidar desta: "Die Würde des Menschen ist unantastbar" (a dignidade da pessoa humana é inviolável). Abre a própria Constituição, separada de tudo o resto, pois tudo o mais surge como concretização desta grande premissa.

Esta orientação tem de ter um sentido substancial, caso contrário seria consequência e não mais fundamento duma ordem normativa. ${ }^{4}$

O que está então por detrás do recurso nas constituições à dignidade da pessoa humana?

\footnotetext{
4 Por isso os autores substancialistas procedem à discriminação no elenco dos direitos constitucionalmente assegurados dos verdadeiros direitos fundamentais. Assim, por exemplo, Manuel Gonçalves Ferreira Filho observa que é indiscutível exagero incluir a exclusividade das marcas de indústria e comércio e a exclusividade do nome comercial no rol dos direitos fundamentais, embora compreendidos no longo elenco do art. 5 da Constituição Federal brasileira.
} 
Está uma realidade substancial: a própria pessoa. É esta necessariamente o elemento essencial a que se referem os próprios textos constitucionais. ${ }^{5}$ A pessoa é o ente ou substância que tem e manifesta aquela dignidade. Impõe-se, pois, para a interpretação da lei, que se desça à análise substancial do ser que é digno, para que se possa compreender por que é revestida de dignidade.

Isso nos obriga a pesquisar mais fundo a noção de pessoa, para ancorar essa dignidade. Só a pessoa nos dá a razão da dignidade, como só a pessoa nos permite apreender as consequências desta.

4. A formulação da noção de pessoa

Enfrentando então a difícil noção de pessoa, temos outra surpresa.

A noção de pessoa é relativamente recente, na evolução da humanidade. Não a encontramos em nenhuma civilização clássica anterior à civilização greco-cristã.

Todas as civilizações até então foram totalitárias, como o continuaram a ser as civilizações que se desenvolveram fora desta matriz. Pode explicar-se como uma resultante de circunstancialismo exterior que impunha uma grande coesão social: o grupo não se poderia deter na consideração das pessoas dos seus membros.

Também a civilização grega foi totalitária. A moral desenvolvida por seus geniais filósofos era ainda a moral perante a pólis. Mas o grego interessa-se pela individualidade, ainda que por outro lado a considerasse uma imperfeição. ${ }^{6}$ Desenvolve-se o que se pode chamar um humanismo, que irradia no mundo de então graças à epopeia de Alexandre Magno.

Numa Palestina já muito helenizada surge Cristo. Da sua doutrina resulta o valor incomensurável da Pessoa, fazendo aparecer à plena luz as consequências de cada homem representar um ser criado à imagem e semelhança de Deus. Por outro lado, e por isso mesmo, há a plena comunhão humana de que todos participam: o homem é um ser com os outros, pelos outros e para os outros, como logo nos primeiros tempos do cristianismo foi perfeitamente entendido.

Sobre esta dupla base é gerada a civilização greco-cristã, ${ }^{7}$ que é aquela em que nos encontramos imersos. Mas nem isso significa que a noção de pessoa logo tivesse

\footnotetext{
5 Enquanto formal ou procedimentalmente emanariam da vontade popular.

6 Desenvolve-se um sentido moral, particularmente nos estóicos, embora a noção de dever em si fosse estranha aos gregos. Profundamente intelectualistas, colocavam o acento no elemento racional, na boa compreensão das coisas: se esta existisse, o homem agiria correctamente.

7 E não judaico-cristã, como frequentemente se diz, porque o contributo judaico foi religioso mas não civilizacional.
} 
sido captada intelectualmente e se impusesse na vida social. A passagem da esfera religiosa para a civil foi lenta.

A noção filosófica de pessoa só foi aperfeiçoada pela escolástica, estimulada pela necessidade de enquadramento das pessoas divinas. Mas tão-pouco a compreensão filosófica implicou a imediata tradução na vida corrente.

O racionalismo foi cedendo o passo a um voluntarismo que se manifesta em múltiplas frentes, a Reforma protestante, o Humanismo, a tese do contrato social... Atinge o ponto de viragem com o Enciclopedismo e a dependência da organização social dos direitos humanos. Com Kant dá-se a perda da base racional, ${ }^{8}$ com o imperativo categórico formulado como comando meramente formal.

Entramos com isto no mundo dos nossos dias, pois dele directamente derivamos. É o mundo que perde de novo o sentido substancial da pessoa, pois no plano exterior ou político apenas se ocupa com o indivíduo como titular de direitos, deixando na obscuridade os deveres e as exigências da comunhão humana.

\section{A perda de sentido ético. A privacidade}

A evolução da ponderação intelectual da pessoa nos séculos XIX e XX foi acidentada. A pessoa tornou-se ponto de referência obrigatório da civilização ocidental, com tendência para a universalização, mas a correspondência da sociedade que efectivamente se construiu a esse paradigma foi muito limitada.

No séc. XIX imperou o liberalismo, propiciado pela dominante burguesa das revoluções contra o Antigo Regime. Consequentemente, desenvolve-se o individualismo, propício à prioridade dada à satisfação dos egoísmos individuais, bem como a projecção política tendencial na democracia formal; em contraponto desenvolvem-se movimentos igualmente materialistas mas de sinal contrário, conducentes a uma luta de classes. É neste enquadramento que se dá a expansão generalizada do sistema.

No séc. XX acentua-se a perda de conteúdo ético do modelo dominante. $\mathrm{O}$ progresso material é entremeado com crises e convulsões profundas e com a divisão do mundo em grandes blocos. No âmbito da sociedade ocidental consolida-se o protagonismo das grandes estruturas económicas, a erupção das massas e a sociedade da adulação, sobre que se arcabouça. O homem só tem direitos e é constantemente lisonjeado pela publicidade, pela propaganda política e pelos meios de comunicação. Tudo se lhe oferece (embora o que efectivamente se lhe atribua seja muito diferente). Deixa-se de atender ao homem concreto: a pessoa essencial é substituída pela Humanidade ou pelo número nas estatísticas

8 Embora em Kant com a salvaguarda substancial da pessoa. 
ou nas sondagens. A comunhão humana deveria levar ao acento na solidariedade mas esta é afinal marginalizada, porque é irrelevante para o funcionamento do sistema.

Com isto chegamos à transição para o séc. XXI, com uma sociedade ocidental globalizante, que faz referência constante à pessoa humana e à sua dignidade, mas formalizada. O cidadão ocupa o centro dos discursos; mas já não é propriamente o cidadão, é antes o consumidor.

A pessoa seria o objectivo da organização da sociedade. Mas o esquema não funciona, porque a pessoa não se pode realizar quando o sentido do que essencialmente caracteriza a pessoa se perdeu para a sociedade. O homem sem deveres, o cidadão-cliente, não dão perspectiva de saída humana à sociedade tecnocrática em que nos encontramos.

Para que o discurso não se torne demasiadamente abstracto, vamos concretizá-lo num ponto fulcral: a privacidade, ou a intimidade da vida privada.

A origem desta categoria, como se reconhece até pelo neologismo privacidade, é norte-americana. Surge nos Estados Unidos da América, por iniciativa de dois autores, no final do séc. XIX. Desenvolvem o right to be alone, como coroamento de uma oposição que é fundamental nos EUA entre vida pública e vida privada. A vida privada deve ser mantida ao abrigo do Estado, concretizando-se nas várias exigências em que a privacidade se vai decompodo.

O direito toma assim um acento egoísta e anti-social. Ignora os aspectos de solidariedade, podendo ser utilizado simplesmente para efeitos como a fuga aos impostos, por exemplo. Mas, elucidativamente, vem a englobar quase todos os direitos de personalidade, na visão norte-americana. O que revela que se não atende primacialmente à pessoa, como ente em comunhão social, mas ao ser individualista e desintegrado que surge carregado de pretensões perante a estrutura colectiva em que se integra.

Não obstante, a privacidade passou à Europa e aos outros lugares onde se estendem a civilização ocidental, ocupando um lugar cimeiro e desdobrando-se em múltiplas restrições e proibições. ${ }^{9}$

Há explicação para que assim tenha acontecido. A sociedade que nos rodeia é uma sociedade tecnologicamente avançada. O homem, no seio dela, é uma mónada altamente vulnerável: as possibilidades de intromissão na vida de cada pessoa são hoje inúmeras e ameaçadoras.

Antes da actual civilização urbana a questão não se colocava. Nas aldeias, todos conhecem a vida uns dos outros e conversam sobre ela. Mas isso não faz com que sejam menos pessoas, não os atinge como tal. Salvo em situações extremas, o que de

\footnotetext{
9 Cfr. o nosso A reserva da intimidade da vida privada e familiar. Revista da Faculdade de Direito de Lisboa, Lisboa, v. XLIII, n. 1, p. 9-25, 2002.
} 
negativo possa haver é compensado pela própria integração grupal, pela solidariedade a nível comunitário, que ampara o desenvolvimento de todos.

Não se passa assim na sociedade urbana. O homem está desarmado e anonimizado perante os outros e perante o Estado. Está sozinho no meio da multidão. Com a informática a sua vulnerabilidade passou a ser extrema, porque pelo cruzamento de dados passou a ser possível reconstituir com prática certeza a vida de cada um. Nomeadamente, passou a ser possível que o Estado, ou máfias poderosas ou os seus cúmplices instalados no poder, descubram sempre algo com que possam destruir quem lhes não convém, com verdade ou com a aparência.

Isto torna assim obrigatórias as cautelas indispensáveis para evitar que da revelação ou do mero conhecimento de dados individuais resulte o afrontamento das pessoas a que respeitam. Mas isso não significa que a privacidade se torne o Direito dos Egoísmos Individuais: ou o Direito que põe a salvo os poderosos da investigação penal. Todo o Direito da Pessoa não pode dispensar a ligação ética que o justifica. A privacidade existe antes de mais para permitir que cada pessoa prossiga, em sua consciência, o seu desenvolvimento pessoal. Fazê-la perder esse norte, torná-la como acontece já hoje frequentemente uma fortaleza do arbítrio, fora de toda a consideração da solidariedade social e dos deveres que dela derivam para com a comunidade é, também aqui, resvalar para o mero formalismo, a justificação fácil e fútil. Só tendo presente a noção substancial de pessoa se encontra o equilíbrio entre os extremos. E só ela nos pode conduzir na interpretação das leis.

Neste sentido, o art. 26/2 da Constituição é prudente, ao determinar que "a lei estabelecerá garantias efectivas contra a utilização abusiva, ou contrária á dignidade humana, de informações relativas às pessoas e famílias".

\section{Pessoa, homem, corpo e genoma}

Se a justificação da dignidade da pessoa está, muito simplesmente, na própria pessoa, não podemos furtar-nos a analisar esta, quaisquer que sejam as dificuldades que se defrontem. Porque sem isso, invocar a dignidade da pessoa é exibir um rótulo em branco.

Comecemos por perguntar que relação há entre Homem e Pessoa.

A nosso ver não há distinção essencial, haverá apenas diversidade na posição do observador. Todo o homem é pessoa e toda a pessoa, no nosso domínio de observação, é homem. Simplesmente, quando se fala em homem tem-se em vista primariamente a base biológica, sem a qual não há pessoa: quando se fala em pessoa tem-se em vista a presença constitutiva do espírito naquele ser. Mas é sempre o mesmo ser que é corpo e espírito. A pessoa é o ser humano, síntese (se a palavra diz tudo) de corpo e espírito. 
Há assim uma unidade essencial, uma vez que o homem, ser vivo, pressupõe necessariamente um corpo. ${ }^{10}$

Daqui deriva, desde logo, que a protecção da pessoa se estende automaticamente ao corpo. E que a defesa da pessoa, que a todos cabe, leve à ilicitude de actos como o suicídio ou a amputação, porque a vida não é um bem disponível.

Como se caracteriza então o corpo humano? A descoberta do genoma permite dar a resposta. O genoma unifica o corpo humano: é corpo tudo o que é expresso pelo mesmo genoma e não o é o que se manifestar por genoma diferente.

O genoma é irrepetível. Mas o genoma não é o espírito. Também não explica o espírito, como se o espírito fosse um derivado do genoma. Estará na base apenas de 20 a 30\% das características e maneiras de ser individuais. Tudo para além disso está fora, com o que se refuta qualquer tentação materialística de explicação. Deixa pois livre o caminho para a admissão de que o espírito humano não se basta com uma referenciação ou epifenómeno de uma base física.

Com isto, ainda que não possamos dizer que a cada genoma corresponde uma pessoa ${ }^{11}$ podemos pelo menos dizer com segurança:

- se há genoma humano, há pessoa humana

- se há genoma humano diferenciado, há pessoa humana diferente

Isto permite ainda uma conclusão muito importante, relativamente ao embrião. Se é o genoma que caracteriza o corpo, logo que ocorre a singamia ou fusão dos núcleos há um corpo humano. Porque o embrião tem logo definitivamente um genoma diferente do da mãe.

Ouve-se dizer com frequência, na apologia do aborto, que o embrião faz parte do corpo da mãe. Donde se conclui: "Do meu corpo faço o que quero!".

Nenhuma das afirmações é verdadeira. Desde logo, o conhecimento do genoma dá um desmentido total. Há, seguramente, uma nova vida humana, diferenciada da vida e do corpo da mãe.

Esta é a base da protecção do embrião. É uma vida humana diferenciada, um ser a quem podem ser reconhecidos fins próprios. O respeito pela pessoa impõe o respeito de cada vida humana, desde o seu início.

\footnotetext{
${ }^{10}$ Sobre esta matéria cfr. por último ALMEIDA, Vasco Duarte de. Sobre o valor da dignidade da pessoa humana. Revista da Faculdade de Direito daUniversidade de Lisboa, v. XLVI, n. , p. 623 e ss, 2005. O autor faz uma aprofundada análise das várias dimensões da pessoa, tripartindo-as entre a corpórea, a individual e a comunicativa. Atribui-nos a limitação apenas a estas duas últimas dimensões, o que não cremos fundado. Não decorre das nossas afirmações de que o homem é um ser ético, mais que biológico, constantes do nosso livro que cita, Direito civil: teoria geral. 2. ed. Coimbra: Coimbra Editora, 2000.

${ }^{11}$ Uma vez que não entramos aqui na análise dos casos especiais representados por gémeos monozigóticos e por embriões clonados.
} 


\section{O anencefálico}

Ilustremos estes princípios com um tema espinhoso, que propicia um delicado banco de ensaios: o estatuto do anencefálico.

A questão ético-jurídica resultante da anencefalia não tem sido muito versada em Portugal, mas provocou vivo debate no Brasil. Podemos aproveitar o precedente como base de reflexão.

Foi levada em 2006 ao Supremo Tribunal Federal, que é o Tribunal Constitucional brasileiro, uma pretensão de autorização do aborto de um feto caracterizado por anencefalia. A lei brasileira não insere a anencefalia entre as causas justificativas do aborto.

O Ministro Marco Aurélio de Melo, a quem coube liminarmente decidir, autorizou o aborto. Mas a liminar foi revogada pelo Plenário, por se não tratar de modalidade de aborto admitida pelo Código Penal.

Suscitou-se debate. Mas a posição tomada pelo STF foi reforçada em 2007 pela publicação duma portaria ${ }^{12}$ em que se exige a parada cardíaca irreversível para a realização dum transplante; em contraste com Resolução tomada sobre a matéria pelo Conselho Federal de Medicina.

Perante isto, como nos situarmos? Supomos que a resposta supõe resolvido um problema prévio: qual o suporte biológico do espírito?

Partimos da afirmação anterior: não há homem sem corpo. Corpo e espírito estão em união indissolúvel na pessoa viva. Mas até onde se chega, na exigência do suporte biológico?

Daniel Serrão procede a este propósito a uma preciosa análise, revelando como na escala animal se diferenciam sucessivamente três sistemas cerebrais que permitem a progressiva ascensão para funções superiores.

Sem nos podermos deter na exposição sequer dos resultados, temos que no cérebro humano, em consequência dessa especialização de zonas, pode-se diferenciar no terceiro sistema, o sistema cortical; e particularmente o chamado neocórtex a que, no dizer de Daniel Serrão, "estão vinculados os comportamentos e capacidades específicas do seres humanos que os singularizam no confronto com todas as outras espécies animais". ${ }^{13}$

\footnotetext{
12 Portaria n. 487, de 2 de Março de 2007.

13 Veja-se $A$ anencefalia e o suporte biológico do espírito (neste mesmo volume), n. 1. Veja-se também a análise das funções cerebrais, nomeadamente da linguagem, em DONALD, Merlin. Origens do pensamento moderno. Lisboa: Gulbenkian, 1999.
} 
Essa função especificamente humana manifesta-se antes de mais na autoconsciência. A partir desta desenvolve-se a actividade a que se chama racional ou intelectual ${ }^{14}$ que vamos tentar acompanhar nas seguintes manifestações:

-a formação de conceitos ou ideias abstractas

-a fala ou a linguagem, faculdade que difere dos modos de comunicação entre as espécies animais porque mobiliza justamente os conceitos ou ideias abstractas formados; é um exercício de abstracção.

Essa actividade prolonga-se no amor, como capacidade especificamente humana, que se distingue, ensina Daniel Serrão, das emoções, que são dependentes de actos perceptivos, ou do desejo sexual, que é essencialmente hipotalâmico. ${ }^{15}$

Com isto transitamos para o mundo da cultura. A cultura é realização de valores, portanto pressupõe necessariamente a sensibilidade aos valores. O homem transforma a natureza pela cultura, criando modos de existência própria, realizando ou prosseguindo o belo, o justo...

E aqui encontramos o elemento básico, decisivo, da consciência moral, orientada para o bem. O homem é sensível a este valor, reflectido na consciência humana. A liberdade, ultrapassando o arbítrio, permite prossegui-lo.

Finalmente, a capacidade de abertura à transcendência. Representa o ponto mais alto na manifestação do espírito humano. Representa-o mesmo para quem pretenda ser também o ponto mais alto de capacidade de erro por parte do homem, porque a abertura religiosa é o diferenciador mais absoluto entre o homem e os restantes animais. Um mito, por mais primitivo, é uma manifestação inegável do espíritio.

Voltemos então ao anencefálico, que sabemos já ser destituído do noecortex.

$\mathrm{O}$ anencefálico tem um genoma próprio, que é inegavelmente um genoma humano. Há uma vida humana. Mas isso bastará para caracterizar o ser humano? Não se requer ainda um corpo que possa ser o suporte do espírito? ${ }^{16}$

O espírito não é uma segregação da matéria. Mas também não pode haver espírito sem o suporte biológico correspondente. A actividade a que chamamos espiritual requer uma base física mínima.

O anencefálico não tem nem nunca poderia ter autoconsciência, capacidade intelectual, consciência moral, abertura à transcendência...

\footnotetext{
${ }^{14}$ Discute-se a qualificação como espiritual, mas parece que tudo o que derive da auto-consciência é necessariamente espiritual.

15 Ibid, n. 3.

${ }^{16}$ Não parece relevar aqui o chamado "espírito de subsistência”, que também os animais possuem.
} 
Então, se são estas actividades que caracterizam o espírito, diremos que o anencefálico, que não possui o necessário suporte biológico, não tem e nunca terá espírito, porque não tem a potencialidade biológica de o abrigar. Haverá pois que concluir que o anencefálico não é um ser humano, porque não há um ser humano quando não se encontra sequer um habitáculo potencial do espírito.

No ponto de vista jurídico, não se pode verificar em relação a ele o tipo do aborto, porque o aborto é um crime contra a pessoa em formação e o anencefálico não é referível a esta figura. Está por natureza excluído do tipo, independentemente de previsão legal.

Não sendo embora uma pessoa, o anencefálico é da ordem das pessoas. Quer dizer, na dicotomia pessoa/coisa, o anencefálico não é coisa, porque participa de elementos que o aproximam em certos aspectos do regime das pessoas. Há uma analogia com o cadáver, que não é seguramente pessoa mas merece um respeito muito particular pela relação em que se encontra com a pessoa. Também o anencefálico, embora não tenha chegado a ser suporte do espírito, tem a afinidade com a pessoa pelo facto de ter provindo de uma gestação humana, embora incompleta ou frustrada; e no caso do anencefálico há ainda uma vida que é vida humana, embora esta não tenha a potencialidade de ser habitada pelo espírito. ${ }^{17}$

Assim, por exemplo, a retirada de órgãos ou tecidos do anencefálico deve ser objecto de cautelas especiais, porque este não é um mero objecto. Esta é a justificação substancial da Portaria brasileira acima mencionada. Acrescem outras razões, fundadas na precaução. Por um lado, porque na dúvida há que tomar perante estas figuras cuja qualificação suscita controvérsia uma posição cautelosamente restritiva; por outro, porque há sempre que recear os abusos, que poderiam levar, sob a alegação de que o anencefálico não é pessoa, a pôr termo a uma vida humana para um aproveitamento em condições óptimas de órgãos que se cobiçam para efeitos de transplante.

8. O direito ao desenvolvimento da personalidade

A Constituição passou a incluir entre os direitos fundamentais, a partir da revisão de 1997, o direito ao desenvolvimento da personalidade (art. 26/1). É o preceito em que a Constituição avança mais no domínio dos direitos de personalidade, começando

\footnotetext{
${ }^{17}$ Haveria também uma aproximação com o que se passa com o clone, para aqueles que excluem a qualificação do clone como uma vida humana (o que não é o nosso caso). O argumento (ou princípio) da dignidade humana como objecção à clonagem reprodutiva é referido no relatório do Parecer do CNECV n. 48/06, de Abril de 2006, n. 1.2.1.1.c, mas fazendo coincidir a dignidade com a imagem que o Homem tem de si mesmo, o que nos parece inaceitável.
} 
pelo direito à identidade pessoal e seguindo-se logo este novo direito ao desenvolvimento da personalidade.

Aparece assim como um direito de cúpula. À primeira vista, é estranho. Dir-se-ia que cada um desenvolve como quer a sua personalidade, sem que interferências exteriores o possam impedir. Mas à luz da tendência ainda dominante em matéria de direitos fundamentais o preceito deverá ser entendido prioritariamente como prevendo que serão criadas e preservadas as condições exteriores propícias ao desenvolvimento pessoal. Embora se sobreponha a outros direitos, liberdades e garantias, tem ainda este sentido útil.

É porém sob a óptica dos direitos de personalidade que a previsão poderia revestir um conteúdo mais rico, que vamos tentar determinar.

A realização da personalidade pressupõe liberdade. É esta a justificação última das várias liberdades que são legalmente reconhecidas. Mas esse não pode ser o conteúdo do direito ao desenvolvimento da personalidade, pois as liberdades são objecto de outras previsões constitucionais.

Porque é livre, o homem é responsável. Há que caracterizar essa responsabilidade. Qual o sentido e objecto desta?

A jurisprudência constitucional alemã deu vida a um "direito geral da personalidade", destinado a cobrir insuficiências da disciplina ordinária, nomeadamente no domínio da responsabilidade civil. Em Portugal a figura é dispensável, perante o numerus apertus dos direitos de personalidade (art. 70/1 do Código Civil). Não adianta nada, é uma superfetação inútil. ${ }^{18}$

Há que esclarecer directamente o que entender por desenvolvimento da personalidade.

É seguro que a categoria tem um pressuposto, que é a autodeterminação. Fala-se normalmente em autonomia, mas autodeterminação é mais amplo, porque autonomia em rigor abrangeria apenas o estabelecimento de regras para si próprio e não as decisões individuais.

Mas o desenvolvimento da personalidade não pode reduzir-se à resultante, qualquer que ela seja, das decisões de cada homem na condução da sua própria vida. Isso seria reduzir tudo a um caixilho, tornando o conteúdo vazio. Falando-se em desenvolvimento da personalidade pressupõe-se necessariamente que ao homem, na sua liberdade e responsabilidade, cabe formar-se a si mesmo, desenvolvendo potencialidades que traz consigo. O que implica que se pressuponha que a personalidade "desenvolvida" é uma realidade positivamente valorada, e portanto uma personalidade que não resulta do

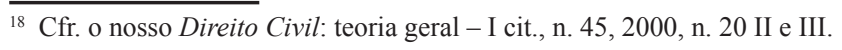


arbítrio ou descaso do sujeito, mas que lhe é proposta por natureza como um fito condutor a realizar.

Quais são então esses elementos positivos? Que valores se firmam? Porque a realização perfeitamente única de cada personalidade se processa num mundo de valorações objectivas que são captáveis e participadas pela comunidade.

Com efeito, seria cómodo dizer que a ordem colectiva é alheia a esses valores, que se encerram no foro íntimo de cada um. Não é assim, porque o Direito traduz essas valorações nas suas regras, maxime penais. E a educação, que todos os Estados tomam a seu cargo, implica necessariamente a transmissão de valores, como a veracidade, diligência, autodomínio... Tal como implica a rejeição dos comportamentos opostos correspondentes e das condutas anti-sociais.

Sem uma tábua de valores, haveria realização da personalidade na opção pela droga, na avareza, no isolamento e na agressividade por ódio à humanidade... Nem uma moral utilitária admitiria estes resultados.

Mas também seria incorrecto remeter tudo para os consensos sociais. Os consensos inter-individuais são necessários, mas não dispensam o enquadramento colectivo. E este requer por sua vez consensos, mas também este consenso global não representa o arbítrio colectivo, mas o esforço para se progredir numa busca plurilateral dirigida a uma aproximação maior do que se possa revelar como correcto, dentro do que é perceptível por cada sociedade histórica.

Há pois que aprofundar sempre mais quais são as exigências da pessoa e da sua realização, como pressuposto de um mais adiantado estado colectivo de regulação e entendimento.

Isto é muito particularmente significativo na voragem da sociedade actual, em que a vida colectiva tende a reduzir-se ao choque dos egoísmos individuais. Até em instituições que se diriam altruístas há antes de mais a apropriação e aproveitamento pelos que estão já instalados e a vedação da participação dos outros. Também os proventos das instituições públicas com autonomia financeira revertem com a maior inocência para os que as ocupam, subtraindo-os à comunidade.

No próprio domínio da ética o utilitarismo coisifica os outros, para aproveitamento próprio. $\mathrm{O}$ estatuto atribuído ao embrião é nesse sentido elucidativo. $\mathrm{O}$ voluntarismo que de início anotámos persiste na ética, na medida em que esta não recorra à justificação substantiva subjacente e se contente com armistícios efémeros de interesses, ou pactos de não agressão. Sobre tudo isso o pós-modernismo toma como objectivo, não a verdade, mas a crítica da verdade. Faz perder toda a base: a ética reduz-se à conveniência, torna-se uma espécie de catálogo de boas maneiras sociais.

Mas se tudo se reduz à liberdade para satisfazer necessidades vitais, não se ultrapassa ainda o nível dos animais, que também usam assim a sua capacidade de optar. 
Onde está então a dignidade da pessoa humana? Só se o estiver na capacidade de escolha do mal pelo mal, ${ }^{19}$ que os animais efectivamente não possuem.

9. A realização da personalidade

A meditação sobre a pessoa leva-nos por outro caminho.

O homem é um ser in fieri.

Goza da auto-consciência, que o diferencia dos outros animais. Tem consciência nomeadamente da sua liberdade. Como tem consciência da possibilidade de se construir a si mesmo.

Há uma dialéctica fundamental na condição humana, que só ganha em ser expressa na sua crueza.

O homem é livre, porque tem a possibilidade de se tornar livre.

O homem é pessoa, porque tem a potencialidade de formar a sua própria personalidade.

Descodificando um pouco, diremos que o homem tem a possibilidade e a responsabilidade de transformar a liberdade formal ou arbítrio em liberdade substancial, pela capacidade que lograr construir em si mesmo de agir com fundamento moral, de harmonia com os fins que para si traçou.

É por ser pessoa, como ser auto-consciente dotado nomeadamente de consciência moral, que pode usar a sua liberdade para construir a personalidade que representa a sua própria realização como ser espiritual.

Parece-nos por isso mais expressivo falar em realização da personalidade que em desenvolvimento da personalidade. Trata-se de uma verdadeira realização, não apenas de um mais descolorido desenvolvimento. Será pois esta a terminologia que utilizaremos, nomeadamente na qualificação deste direito, como direito à realização da personalidade.

Ora bem: a dignidade do homem radica nesta capacidade e neste encargo da auto-construção. São estes que o distinguem e superiorizam.

Mas então, o homem é digno porque é pessoa. ${ }^{20} \mathrm{~A}$ dignidade não lhe é atribuída de fora, não é um a mais, é intrinsecamente decorrente da própria característica de ser pessoa, que é dialecticamente unitária desde a concepção até à morte.

O homem é pois digno porque é dele constitutivo um projecto a realizar. Alardear dignidade sem atender à essência do homem é girar no vácuo. Por isso a

\footnotetext{
${ }^{19}$ Como é expresso na afirmação da personagem de Shakespeare: "Estou decidido a tornar-me um vilão".

${ }^{20}$ Neste sentido, expressamente, OTERO, Paulo. Instituições políticas e constitucionais. Coimbra: Almedina, 2007, 1.2-4.
} 
universalizada referência à "eminente dignidade da pessoa humana" soa a oco, enquanto estiver esvaziada da sua essência.

Devemos antes afirmar que o homem é um universo único e irrepetível, com liberdade e potencialidade de auto-realização.

Sintetizando: o homem tem dignidade porque é pessoa. É um ser ético, porque é auto-consciente e dotado antes de mais de autodeterminação e consciência moral. Não é apenas um ser biológico ou um ser ao sabor do arbítrio: é um ser com fins de realização próprios. É responsável pela condução da sua vida. Nisso reside a sua dignidade. ${ }^{21}$

\section{O outro: a comunhão}

Falta porém nesta recolha de fundamentos um elemento essencial: o outro.

O homem é um ser em relação. O outro é constitutivo da sua realidade humana, no ponto de vista corpóreo e espiritual. O outro é simultaneamente realidade ontológica e dado imediato da consciência.

Encontramos, todavia com frequência a afirmação que a pessoa é relação ${ }^{22}$. Será por um lado uma indevida influência da fenomenologia, que não aceitamos, e por outro lado um tardo reflexo da escolástica. Esta corrente, trabalhando a noção de pessoa para caracterizar as pessoas divinas, concluiu que estas são (também) relação, porque em Deus não há acidente. A conclusão não encontra paralelo que permita a transposição para a pessoa humana.

O homem não é relação: o homem está em relação. A diversidade dos verbos, que é uma das mais valias da língua portuguesa por contraposição a línguas de curso mais frequente, traduz perfeitamente esta diversidade. Cada homem é uma substância, um universo completo, mas de novo dialecticamente, só se realiza espiritualmente com os outros e para os outros.

O sentido do homem como ser comunitário é um legado da filosofia europeia. Mas também esse sentido se perde com a transformação operada no séc. XVIII. O outro, contraposto ao homem só com direitos, passa a representar um obstáculo. Porque o outro

\footnotetext{
${ }^{21}$ Isto funda, sem necessidade de recorrer a desenvolvimentos que seriam deslocados, a base mínima de toda a afirmação consistente da dignidade da pessoa humana.

22 Afirmação sublinhada e repetida por exemplo por KAUFMANN, Arthur. Prolegómenos a uma lógica jurídica e a uma ontologia das relações. Boletim da Faculdade de Direito, Coimbra, v. LXXVIII, p. 183-203, 2002. Afirma mesmo que não considera real "a pessoa como tal" e distingue pessoa de criatura humana. Uma criatura humana, afirma como mera substância, também existe no isolamento, enquanto que a pessoa, ao contrário, só existe "entre as criaturas humanas" (p. 203). Com todo o devido respeito parece-nos que, mais que uma divergência de orientação filosófica, há uma arbitrária manipulação semântica do termo pessoa, que é nociva para a compreensão do que está verdadeiramente em jogo.
} 
teria igualmente direitos, haveria que conciliar. A fórmula encontrada foi: a tua liberdade cessa onde começa a liberdade dos outros.

Isto era próprio do individualismo e liberalismo, mas o outro ficaria deste modo reduzido a desempenhar uma função negativa. Não é essa a visão personalista. A ligação aos outros é uma ligação de comunhão. Dessa comunhão deriva a solidariedade. Por isso Diogo Costa Gonçalves, na linha da categoria escolástica do homem como distinctum subsistens, acrescenta: distinctum subsistens respectivum e contrapõe a solidão ontológica à inter-subjectividade, para evidenciar a relação como "dimensão constitutiva do Homem". ${ }^{23}$

A ligação é tão funda que a realização pessoal, passa necessariamente pela realização dos outros, pelo empenhamento total nessa realização. $\mathrm{O}$ auto-sacríficio pelos outros é conforme à ordem jurídica. Esta não pode levar até ao fim o valor de realização pessoal na pressuposição do sacrifício pelos outros, mas valora-o positivamente. Além disso são impostos sacrifícios tendo em vista o bem comum.

O séc. XX realizou parcialmente esta reabilitação do bem comum. A função social, as cláusulas gerais como a boa fé, a eticização do direito em geral marcaram um processo de viragem. Mas isso fez-se no meio de muitas contradições, porque o espírito materialista e de exacerbado antagonismo do capitalismo não permitiu um desenvolvimento coerente dos pressupostos.

Num livro notável que veio entrementes a lume Paulo Otero, que muito consideramos, encara com suspeita o "bem comum", como se fosse uma categoria transpersonalista. ${ }^{24}$ Esta leitura não só não é forçosa como condena sem motivo uma expressão que traduz da forma mais rica o direccionamento da pessoa a uma comunhão com os outros. Ela traz a responsabilização de cada membro pelos fins da comunidade e impõe eticamente a sua participação nos esforços colectivos.

Em qualquer caso, a realização humana que se supõe não é uma realização egoísta, um abandono ao arbítrio ou um isolamento social. É uma realização de valores e uma responsabilização pelos outros. Os "direitos humanos" nunca podem representar para o Direito a criação de zonas de indiferença.

Por isso, o dever é uma categoria tão normal como a do direito, que traduz a integração social; o dever compõe necessariamente a condição humana e exprime a comunhão constituinte da pessoa. Quer os deveres interindividuais quer os deveres para com a comunidade são deveres éticos, sobre os quais se arquitectam os correspondentes

\footnotetext{
${ }^{23}$ Em GONÇALVES, Diogo Costa. Tutela da personalidade e personalidade ôntica: a juridicidade da realidade pessoal. Relatório de mestrado apresentado na Faculdade de Direito de Lisboa, p. 32-36.

${ }^{24}$ OTERO, Paulo. Instituições políticas e constitucionais. Coimbra: Almedina, 2007, em várias referências, nomeadamente na p. 35.
} 
preceitos jurídicos. Os deveres não são assim excepções, são antes manifestação normal da interdependência das pessoas na sua auto-realização.

\section{O Direito da Pessoa}

Com isto voltamos à referência aos direitos e deveres fundamentais, que nos deu o ponto de partida.

A linguagem dos direitos que se instaurou, ainda por cima numa linguagem de direitos sem deveres, ou pelo menos em que os deveres surgem em plano meramente secundário, representa efectivamente uma distorção da visão da pessoa.

Se a pessoa é um ser in fieri, com a potencialidade e o encargo da auto-realização, o dever é tão importante como o direito, porque não há realização pessoal que se possa fazer contra ou até sem os outros.

A ordem jurídica não pode impor aos seus membros nem o se nem o como da realização pessoal, mas deve estabelecer os seus quadros tendo como base ou pano de fundo a solidariedade. Mas a sociedade da lisonja corrói esse modelo, porque assenta na simulação de um preito à soberania do individuo a quem tudo é oferecido e nada será pedido. A ociosidade e o prazer são os grandes aliciantes - vejam-se os anúncios publicitários. É de supor que esse modelo continue a desagregar a nossa sociedade, como o panem et circenses destruiu a sociedade romana.

A visão essencial da pessoa em comunhão frutificará nas manifestações próprias de cada ramo do Direito. No Direito Constitucional, justificará os direitos e deveres fundamentais. Mas a base substancial destes está em serem emanações da pessoa e não meras criações do Direito Positivo.

No livro que acabamos de referir Paulo Otero inicia uma exposição do Direito Constitucional com um volume inteiramente dedicado à pessoa humana e ao Estado de direitos humanos. ${ }^{25}$ É um acontecimento, sabendo-se que para o autor os direitos humanos são necessariamente ancorados na pessoa humana.

A pessoa deve ser igualmente a chave do Direito Privado e de todo o restante Direito. A pessoa supõe uma caracterização ontológica. Como ser em realização, implica necessariamente integração comunitária, com os deveres que a esta são inerentes.

Tal significa que, enquanto se estuda a pessoa, tudo tem de ser medido pelo conteúdo ético. Assim, só haverá um direito de personalidade à imagem quando a personalidade estiver em causa. $\mathrm{O}$ artista que cobra dinheiro pela utilização da sua imagem não exerce um direito de personalidade, mas uma faculdade patrimonial como qualquer outra.

\footnotetext{
${ }^{25}$ OTERO, Paulo. Instituições politicas e constitucionais. Coimbra: Almedina, 2007. v. 1.
} 
Também os deveres fundamentais ou decorrentes da personalidade são eticamente determinados, não ganhando essa natureza pela circunstância formal de terem sido efectivamente previstos na Constituição ou noutra lei.

Isto permite uma distinção nítida do Direito da Pessoa e do estudo da personalidade jurídica que é feito na Teoria Geral da Relação Jurídica. Aí, o ponto de partida é dado por uma figura técnica, a relação jurídica, e não por uma categoria ontológica, a pessoa. Consequentemente, ainda que se fale na pessoa, o que está em causa é a categoria funcional do sujeito da relação jurídica - portanto, quem quer que na relação jurídica desempenhe o papel técnico de titular de poderes e deveres em relação. A "personalidade jurídica" de que se fala é formalizada - é a mera susceptibilidade de ser titular de direitos e obrigações, susceptibilidade que repousa na opção que tiver sido tomada pela ordem jurídica a esse propósito. Por isso surge em igualdade de condições com a pessoa humana a categoria da pessoa colectiva. Até a sociedade comercial é pessoa jurídica para a lei. Isto não tem já nada que ver com uma consideração substancial da pessoa.

Mas é esta consideração substancial que deve estar à cabeça de todo o Direito. A célebre sentença de Hermoginiano, talvez fruto duma intuição, impõe-se com plena validade: hominum causa omne ius constitutum est. Há que a retomar e levar até ao fundo, para chegar a um Direito deveras fundado na dignidade da pessoa humana.

A pessoa, repisamos, tem dignidade porque é pessoa. Os direitos humanos que se lhe reconhecem têm como fundamento essa dignidade, provinda da capacidade de auto-realização da personalidade. O mesmo fundamento têm os grandes deveres básicos, que dão quadros para a realização humana. Todos abrem caminho a essa realização. Mas a concretização só ao próprio incumbe, embora só a possa realizar em comunhão com todos os outros.

\section{Incidência sobre a Teoria Geral do Direito Civil}

Propomo-nos finalizar com uma breve aplicação à sistemática da Teoria Geral do Direito Civil.

Consideramos esta disciplina verdadeiramente nuclear. É ela que funda as grandes traves-mestras de todo o Direito, na sequência do ius civile.

Mas na maneira de abordar a disciplina há logo à partida uma divergência fundamental.

Há quem parta da relação jurídica e consequentemente proceda desde logo à caracterização desta, só vindo a encontrar a pessoa num momento mais adiantado. Assim procedeu Manuel de Andrade, que só considerava a pessoa funcionalmente, como elemento 
da relação jurídica; ${ }^{26}$ e assim procede hoje Menezes Cordeiro, que após uma Introdução à Teoria Geral entra logo na análise das Situações Jurídicas e do Negócio Jurídico, só no tomo III considerando a pessoa. ${ }^{27}$

Como é natural, afastamo-nos radicalmente desta posição. Se todo o Direito se centra na pessoa, há antes de mais que fixar a essência e as implicações deste núcleo determinante. ${ }^{28}$

$\mathrm{Na}$ orientação mais comum, começa-se por fixar os elementos com que o Direito trabalha, começando pela pessoa e pelos bens. E isto quer se tomem ou não esses dados como elementos da relação jurídica.

Assim procedemos também, procurando todavia quanto possível autonomizar esta matéria da disciplina técnica das situações. Preocupámo-nos com demonstrar o carácter pré-legal de alguns destes elementos: não seriam apenas básicos, seriam mesmo prévios à valoração jurídica.

Mas deparávamos sempre com a dificuldade de uma certa mistura de elementos pré-legais e elementos técnicos, que obscurecia a análise.

Particularmente, a dificuldade suscitava-se a propósito da pessoa. Era necessário tratar sob a mesma epígrafe, quer os aspectos ontológicos, quer outros aspectos exclusiva ou prevalentemente técnicos, como a personalidade colectiva, já referida, ou a capacidade jurídica.

Perante uma categoria tão determinante como a pessoa essa consequência pareceu-nos insustentável, porque ofuscava o significado da pessoa pela junção desta a figuras de mera técnica jurídica.

Dirigimo-nos agora para uma sistemática muito mais radical.

Toda a Teoria Geral deve ser encimada pelo ramo determinante de todo o Direito - o Direito da Pessoa.

Aí deve ser exposta, quer a caracterização essencial da pessoa, quer as implicações directas desta - nomeadamente o que respeita aos direitos de personalidade e aos "deveres de personalidade". Traça-se o estatuto fundamental da pessoa, em que se traçarão também as directrizes fundamentais decorrentes da caracterização da pessoa como ente em comunhão.

\footnotetext{
${ }^{26}$ ANDRADE, Manuel de. Teoria geral da relação jurídica: sujeitos e objecto. Coimbra: Almedina, 1960.

${ }_{27}$ CORDEIRO, António Menezes. Tratado de direito civil: parte geral. 3. ed. Coimbra: Almedina, 2005. t. 1.

${ }^{28}$ Note-se que CORDEIRO, António Menezes. Tratado de direito civil português: parte geral - pessoas. 2. ed. Coimbra: Almedina, 2007. t. 3, aborda várias questões a que os livros jurídicos normalmente se furtam, nomeadamente as ligadas à Bioética, e resolve-as no sentido substancial. Há assim um acatamento implícito da prioridade ontológica da pessoa, como guia necessário do entendimento da ordem jurídica, nunca podendo resultar da mera consideração formal da personalidade jurídica como mera susceptibilidade de direitos e obrigações.
} 
Seria ainda aí que se faria a ponte entre direitos (e deveres) de personalidade e as categorias que concorrentemente e com pouca ligação com aqueles têm sido desenvolvidas, sobretudo os direitos fundamentais e os Direitos Humanos.

Aí caberão também ramos emergentes que têm andado sem pouso certo na enciclopédia jurídica, mas que pelo menos nos seus aspectos determinantes pertencem ao Direito da Pessoa. Pensamos particularmente no Direito da Bioética. Este é na base um Direito da Pessoa em si, na conjugação do corpo e espírito, nas fases sucessivas de começo da vida, dos cuidados em vida e do final da vida.

Versado o Direito da Pessoa, entra-se então no estudo técnico das pessoas, bens, acções e situações jurídicas, mas já aliviado da consideração ex professo das incidências da personalidade ontológica. Tal terá particular significado no estudo das pessoas, agora como sujeito das situações jurídicas. E nomeadamente permitirá estudar aí direitos pessoais que têm andado confundidos com os direitos de personalidade mas que não têm peso ético que o justifique. Isso tornará por outro lado clara a vantagem do estabelecimento de fronteiras, pois a essas figuras, impropriamente integradas muitas vezes nos direitos de personalidade, não se aplica o regime excepcionalíssimo que a lei portuguesa traça para os verdadeiros direitos de personalidade, por carecerem do fundamento ético que o regime legal pressupõe.

É uma pequena revolução no seio da Teoria Geral do Direito Civil. Mas que representa, a nosso ver, uma imposição da projecção da pessoa no mundo do Direito.

Lisboa, 2008.

\section{Refências}

ALMEIDA, Vasco Duarte de. Sobre o valor da dignidade da pessoa humana. Revista da Faculdade de Direito daUniversidade de Lisboa, v. XLVI, n. , p. 623 e ss, 2005.

ANDRADE, Manuel de. Teoria geral da relação jurídica: sujeitos e objecto. Coimbra: Almedina, 1960.

ASCENSÃO, José Oliveira. Direito civil: teoria geral. 2. ed. Coimbra: Coimbra Editora, 2000.

. A reserva da intimidade da vida privada e familiar. Revista da Faculdade de Direito de Lisboa, Lisboa, v. XLIII, n. 1, p. 9-25, 2002.

BARRETTO, Vicente de Paulo. A idéia de pessoa humana e os limites da Bioética. In: BARBOSA, Heloísa Helena et al (Orgs.). Novos temas de biodireito e bioética. Rio de Janeiro/São Paulo: Renovar, 2003. 
CORDEIRO, António Menezes. Tratado de direito civil: parte geral. 3. ed. Coimbra: Almedina, 2005. t. 1 .

DONALD, Merlin. Origens do pensamento moderno. Lisboa: Gulbenkian, 1999.

GONÇALVES, Diogo Costa. Tutela da personalidade e personalidade ôntica: a juridicidade da realidade pessoal. Relatório de mestrado apresentado na Faculdade de Direito de Lisboa, p. 32-36.

KAUFMANN, Arthur. Prolegómenos a uma lógica jurídica e a uma ontologia das relações. Boletim da Faculdade de Direito, Coimbra, v. LXXVIII, p. 183-203, 2002.

OTERO, Paulo. Instituições políticas e constitucionais. Coimbra: Almedina, 2007.

SOUSA, Rabindranath Capelo de. $O$ direito geral de personalidade. Coimbra: Coimbra Editora, 1995. 